\title{
Modelling and Inversion of Ground Magnetic and Electromagnetic Data for Delineation of Subsurface Structures at Siloam Hot Spring in the Soutpansberg Basin*
}

\author{
Peter K. Nyabeze, Oswald Gwavava \\ Department of Geology, University of Fort Hare, Alice, South Africa \\ Email:201013945@ufh.ac.za
}

How to cite this paper: Nyabeze, P. K., \& Gwavava, O. (2018). Modelling and Inversion of Ground Magnetic and Electromagnetic Data for Delineation of Subsurface Structures at Siloam Hot Spring in the Soutpansberg Basin. Journal of Geoscience and Environment Protection, 6, 109-123. https://doi.org/10.4236/gep.2018.611009

Received: September 20, 2018

Accepted: November 18, 2018

Published: November 21, 2018

Copyright $\odot 2018$ by authors and Scientific Research Publishing Inc. This work is licensed under the Creative Commons Attribution International License (CC BY 4.0).

http://creativecommons.org/licenses/by/4.0/

\begin{abstract}
Geophysical surveys utilising magnetic and electromagnetic techniques were carried out at the Siloam hot spring. The spring is in the Soutpansberg Basin in the northern part of South Africa. The research was to investigate groundwater bearing structures at the hot spring. Magnetic survey results showed that the spring occurs between two north dipping dykes. The two dykes could be faulted segments of a single dyke or sill. Magnetic susceptibility results highlighted the presence of metamorphic and volcanic rocks. Electromagnetic survey results showed that the hot spring was within a roughly east to west trending, zone with high electrical conductivity values. Based on the survey results, water is exploiting fractures in the dyke or sill.
\end{abstract}

\section{Keywords}

Electromagnetic, Hot Spring, Magnetic, Modelling, Susceptibility

\section{Introduction}

Ground magnetic and electromagnetic surveys were carried out at the Siloam hot spring in the Soutpansberg Basin located in northern South Africa. The Siloam hot spring has water with temperature above $65^{\circ} \mathrm{C}$. Ground magnetic surveys were carried out across the Siloam hot spring and delineated two east-west striking dykes with a separation of approximately $135 \mathrm{~m}$, located to the north and south of the hot spring, respectively (Nyabeze, Venter, Olivier \& Motlakeng, 2010). Inversion of the magnetic data retained depths of approxi-

*Using geophysics techniques to investigate groundwater bearing structures at Siloam hot spring. 
mately $650 \mathrm{~m}$ for the dykes. High electromagnetic conductivity values were obtained across the Siloam Fault due to mud flows that were induced by excess rainwater (Brandl, Mitchev, Stettler, Graham, \& Smit, 2001). Three zones with high electromagnetic derived conductivity values above $100 \mathrm{mS} / \mathrm{m}$ namely a central zone associated with the spring, a southern zone and a north zone associated with the Siloam Fault were previously delineated (Nyabeze, Venter, Olivier, \& Motlakeng, 2010). The geology of the survey area was reported to consist of sedimentary and volcanic rocks overlying metamorphic and igneous rocks (Barker, Brandl, Callaghan, Eriksson, \& van Der Neut, 2006).

\section{Background}

\subsection{Ground Magnetic Surveys}

A fratured zone was deleneated at the Ikogosi warm spring in south-western Nigeria from magnetic data (Ojo, Olorunfemi, \& Falebita, 2011). Ground magnetic data was used to estimate shallow depths to magnetic sources in the 0 to $160 \mathrm{~m}$ range for near surface bedrock investigations (Kayode, Adelusi, \& Nyabeze, 2011; Kayode, Adelusi, \& Nyabeze, 2013; Peters, 1949). The application of 3-D voxel inversion in theinterpretation of magnetic data, that involves applyig a technique called Magnetization Vector Inversion (MVI), which incorporates both remanent and induced magnetization without prior knowledge of the direction or strength of remanent magnetization, a basis of the $\mathrm{VOXI}^{\circledR} 3-\mathrm{D}$ inversion software (Ellis, de Wet, \& Macleod, 2012). The Mag2D interactive computer program was used to model 2 1/2-dimensional magnetic data (Nutter, 1981). The ZondMag 2D routine carries out modelling and computations that considers the geomagnetic parameters of the study area, such as the declination and inclination of the magnetic induction vector, the value of the normal field, the magnetic susceptibility of the host rocks and the topography (Zond, 2010).

\subsection{Magnetic Susceptibility}

Magnetic susceptibility is defined as the degree to which a body can be magnetised (Buschow \& de Boer, 2003; Dalan, 2006). Magnetic susceptibility can be measured directly using borehole techniques and at a reasonable small spatial-scale using in-phase electromagnetic induction measurements (Dalan, 2006; Dearing, 1994). Magnetic susceptibility in the field can only be measured on outcrops or rock samples (Telford, Geldart, \& Sheriff, 1990). In the study of variation of magnetic properties of soil in Botswana including an area overlying the Limpopo Mobile Belt, the magnetic susceptibility values were found to be an indication of the bedrock and identified paramagnetic or antiferromagnetic minerals without magnetite, ferromagnetic minerals with magnetite, ferrimagnetic minerals with iron oxide minerals, as well as diagenetic minerals with negative or very low magnetic susceptibilities (Ranganai, Moidaki, \& King, 2015). Magnetic susceptibility is dimensionless in the SI unit system (Cano, Cordova-Fraga, Sosa, Bernal-Alvarado, \& Baffa, 2008; Collinson, 2013; Lecoanet, Lévêque, \& Segura, 
1999). To avoid confusion in scientific literature i.e. SI or cgs unit system, the unit system is specified. A multiplication factor of $1 / 4 \pi$ was applied to convert bulk magnetic susceptibility values from SI to cgs units (Ranganai, Moidaki, \& King, 2015; Cano, Cordova-Fraga, Sosa, Bernal-Alvarado, \& Baffa, 2008). In this study it is the SI unit system that is used. Stated that magnetic susceptibility values above and below a value of $0.5 \times 10^{-3}$ SI were indicative of paramagnetic plus diagenetic minerals and paramagnetic and ferromagnetic minerals, respectively (Cano, Cordova-Fraga, Sosa, Bernal-Alvarado, \& Baffa, 2008). Paramagnetic and ferromagnetic materials were defined as having a magnetization vector that is in the same direction as the external field and diamagnetic if the direction was opposite the external magnetic field (Cano, Cordova-Fraga, Sosa, Bernal-Alvarado, $\&$ Baffa, 2008). The effective depth of penetration of the Exploranium KT-9 kappameter for measuring magnetic susceptibility was reported to be in the range of 2 to $3 \mathrm{~cm}$ (Lecoanet, Lévêque, \& Segura, 1999). Meta-volcanic and dykes have magnetic susceptibility values of 0.01 to $0.09 \times 10^{-3} \mathrm{SI}$ (Exploranium, 1995). Magnetic susceptibility values in the range 0.2 to $3.5 \times 10^{-3}$ SI that corresponded to magnetic anomalies for buried soil investigations were reported for Rustad and Hopeton Earthwork sites in North Dakota and Ohio, USA (Dalan, 2006). Magnetic susceptibility values of $700 \times 10^{-3}$ SI have been recorded for rocks with corresponding magnetite content of up to 20\% (Ferguson, Young, Cook, Krakowka, \& Tycholiz, 2016). Basalt and dolerite rock types had typical magnetic susceptibility values between $4 \times 10^{-3}$ and $60 \times 10^{-3}$ SI and that the values could be decreased by metamorphism (Clark \& Emerson, 1991).

\subsection{Electromagnetic Surveys}

Electromagnetic techniques have been used for several years for mapping the electrical conductivity distribution in the subsurface (Monteiro Santos, 2004). Sub-surface, water-bearing structures were delineated at hot springs in the southeastern part of South Africa from results of electromagnetic surveys (Madi, Nyabeze, Gwavava, Sekiba, \& Zhao, 2016). The EM34-3 conductivity meter can give useful results where the earth can be approximated by a two-layer model (McNeill, 1985). The effective depth of investigation using the $10 \mathrm{~m}$ to $40 \mathrm{~m}$ coil separations in the horizontal (HD) and vertical (VD) configurations varies from $7.5 \mathrm{~m}$ to $60 \mathrm{~m}$, respectively (McNeill, 1980). The main components of the EM34-3 system are as follows (McNeill, 1980): The Geonics model EM34-3 frequency domain system comprising separate receiver and transmitter coils that couple inductively with the ground; The technique involves generating an electromagnetic field that induces currents in the earth; the resultant magnitude and phase of the induced electromagnetic currents are related to the subsurface electrical conductivity; The system transmits electromagnetic waves at three frequencies of $6400 \mathrm{~Hz}, 1600 \mathrm{~Hz}$, and $400 \mathrm{~Hz}$ with coil separations of $10 \mathrm{~m}, 20 \mathrm{~m}$, and $40 \mathrm{~m}$, respectively; The receiver and transmitter coils are oriented to operate in either the HD or the VD configuration. The 1-D laterally constrained inversion ap- 
proach was used to model EM34-3 data acquired for cave detection and hydrogeological studies through application of the EM4Soil program (Monteiro Santos, Almeida, Castro, Nolasco, \& Mendes-Victor, 2002). The EM4Soil program was described as a partially informed inversion approach to model multi frequency electromagnetic data used to generate 2-Dimensional geoelectric sections, where some input parameters in the form of prior information are provided by the user (Monteiro Santos, Almeida, Castro, Nolasco, \& Mendes-Victor, 2002).

\section{Methodology}

\subsection{Ground Magnetic Surveys}

The magnetic technique involves measuring variations of the Earth's magnetic field and using the results to study localised geological structures. Ground magntic surveys were carried out along accessible areas near the hot spring in May 2009. The survey lines were generally oriented from north to south in order to intersect the regional geological trend. Total field magnetic values were recorded using Caesium vapour and proton precession magnetometers. The accuracy of Caesium vapour magnetometer models Scintrex NaVmag SM5 and Geometrics G859 was 0.01 (Geometrics, 2011). The accuracy of the proton precession magnetometer models Geometrics 856 and Geotron G5 was $0.1 \mathrm{nT}$ (Geometrics, 2007). Two proton precession magnetometers, Geometrics model G856 and Geotron model G5, were used as base station magnetometers. The Caesium vapour magnetometers had in-built GPS units that facilitated the recording of position and elevation data. The base station magnetometers recorded data at 60 second intervals. Ground magnetic data was recorded every 1 second, using sensors at a height of $2.5 \mathrm{~m}$ to ensure the measurement of high-resolution data at an average station spacing of $1.25 \mathrm{~m}$. Some traverses were surveyed using the Geometrics G856 magnetometer at $10 \mathrm{~m}$ station intervals. Spurious single point data anomalies were filtered from the dataset; these were attributed to cultural objects such as fences, buried tins and wires. The base station data was used to correct the traverse data for diurnal variations using the Magmap 2000 software. The corrected data were gridded to produce images using the Geosoft Software (Geosoft, 2014). The magnetic data was presented as profiles. The magnetic data was modelled to get the best geological fit for the observed field data. Magnetic data were modelled into 2-Dimensional models using the Mag2D software. Ground magnetic data were modelled using the Geosoft VOXI ${ }^{\circledR}$ inversion software to generate 3-Dimensional models (Geosoft, 2013). The magnetic susceptibility data were used to constrain magnetic models. The ZondMag2D software was used for forward modelling and inversion of magnetic data.

\subsection{Magnetic Susceptibility}

The magnetic susceptibility $(\chi)$ was defined as the degree to which a substance 
could be magnetized and mathematically, the ratio of the magnetization $(M)$ to the magnetic field $(H)$ (Buschow \& de Boer, 2003; Exploranium, 1995) as in Equation (1):

$$
\chi=\frac{M}{H},
$$

The magnetic susceptibility $(\chi)$ was inversely proportional to temperature $(T)$ according to Curie's Law and related by the Curie constant $(C)$, for ideal paramagnetic materials below the Curie temperature, as in Equation (2) (Buschow \& de Boer, 2003):

$$
\chi=\frac{C}{T},
$$

Magnetic susceptibility measurements were recorded using a Exploranium KT-9 magnetic susceptibility meter with a capability to measure up to $999 \times 10^{-3}$ SI units. This was done to confirm the association between lithology and magnetic source rock.

\subsection{Electromagnetic Surveys}

The apparent conductivity, $\sigma_{a} \cdot(\mathrm{ohm} \cdot \mathrm{m})$ is given by Equation (3) (McNeill, 1980):

$$
\sigma_{a}=\frac{4}{\left(\omega \mu_{o} s^{2}\right)}\left(\frac{H_{s}}{H_{p}}\right),
$$

where $H_{s}$ is the secondary magnetic field at the receiver coil, $H_{p}$ is the primary magnetic field at the receiver coil, $\omega$ is the angular frequency, $\mu_{o}$ permeability of free space and $s$ is the intercoil separation.

In the frequency domain, the maximum depth of investigation is the skin depth $\delta_{f d}(\mathrm{~m})$ at which the electromagnetic field is reduced to $1 / e$, or $37 \%$ of its value at the surface and is given by Equation (4) (Spies, 1989):

$$
\delta_{f d}=\sqrt{\frac{2}{\sigma \mu_{O} \omega}},
$$

where $\sigma$ is the electrical conductivity and $\mu_{O}$ is the magnetic permeability.

The relative contribution to the secondary magnetic field arising from a thin layer at any depth $Z$ is represented by a function $\emptyset_{V, H}(z)$. The relative contribution $R_{V, H}$ to the secondary magnetic field from all materials below depth $Z$ is given by Equation (5) (Monteiro Santos, 2004; McNeill, 1980):

$$
R_{V, H}=\int_{Z}^{\infty} \varnothing_{V, H}(z) d z,
$$

where $V$ is the vertical coil orientation and $H$ is the horizontal coil orientation.

The apparent conductivity $\sigma_{a}$ for a layer measured using a coil with a separation $s$ with vertical and horizonal coil orientation measurements of $\sigma_{1}$ and $\sigma_{2}$, respectively is given by Equation (6) (McNeill, 1985b):

$$
\sigma_{a}(s)=\sigma_{1}[1-R(z / s)]+\sigma_{2} R(z / s),
$$

then the apparent conductivity for a coil separation $s=10 \mathrm{~m}$ is given by Equa- 
tion (7):

$$
\sigma_{a}(10)=\sigma_{1}+\left(\sigma_{2}-\sigma_{1}\right)(R(z /(10)))
$$

The same relationship holds true for coil separation values $s$ of $20 \mathrm{~m}$ and $40 \mathrm{~m}$ (McNeill, 1985b). The surveys were carried out using a Geonics model EM34-3 frequency domain system with separate receiver and transmitter coils that couple inductively with the ground. The system transmitted electromagnetic waves at three frequencies of $6400 \mathrm{~Hz}, 1600 \mathrm{~Hz}, 400 \mathrm{~Hz}$, with coil separations of $10 \mathrm{~m}$, $20 \mathrm{~m}$ and $40 \mathrm{~m}$ respectively. The receiver and transmitter coils were oriented to operate in either the horizontal (HD) or the vertical dipole (VD) configuration. Surveys were carried out near the Siloam hot spring across and perpendicular to the zone of interest during the dry season, in June 2009, May 2011, and July 2011 respectively to minimize the high electrical conductivity contribution of meteoric water. To generate 2-D geoelectric sections, ground terrain conductivity data were acquired using a combination of dipoles or coil orientations.

\section{Results}

\subsection{Ground Magnetic Surveys}

The magnetic survey site characteristic values are shown in Table 1. Magnetic anomalies withresidual total field values above $400 \mathrm{nT}$ were obtained.

The Siloam hot spring occurs in a low magnetic intensity zone between two interpreted dykes or sills. The location of the east-west trending Siloam Fault was interpreted to be occurring between the dykes or sills (Figure 1).

The profile that was modelled to generate 2-D inversion models is marked by points A and B (Figure 1). The RMS error was minimised to below $10 \%$ for the inversion routine. Interpreted dykes located north and south of the hot spring are the impermeable layers that confine the aquifer, as seen in the magnetic inversion model (Figure 2) with the spring located within a $100 \mathrm{~m}$ to $150 \mathrm{~m}$ wide fault zone. The magnetic susceptibility value for the dykes was $94.7 \times 10^{-3}$.

A 2-Dimensional model was generated using the ZondMag2D software and it confirmed the presence of two dykes or sills near the spring. The magnetic

Table 1. Magnetic magnetic survey site characteristic values.

\begin{tabular}{cc}
\hline Description & Parameter \\
\hline Survey Dates & May, 2009 \\
Declination in decimal degrees & -14.1091 \\
Inclination in decimal degrees & -60.8233 \\
Regional Total Field in nT & 29408.81 \\
Magnetic Model & IGRF \\
Latitude (degrees) & -22.9 \\
Longitude (degrees) & 30.19 \\
Sensor Elevation (m) & 2.5
\end{tabular}




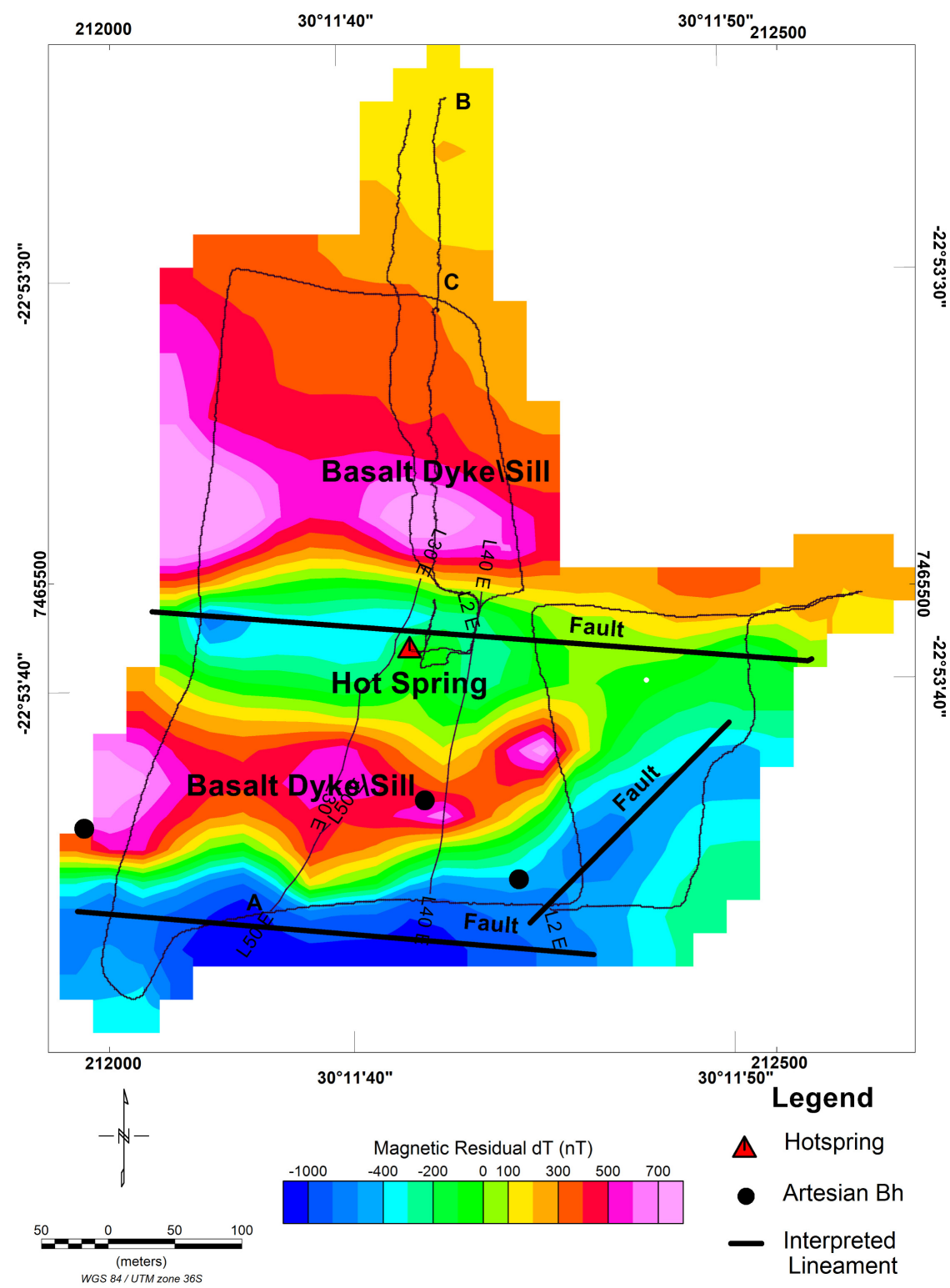

Figure 1. Ground magnetic data, showing interpreted geology, lineaments, location of the hot spring and recent artesian boreholes, with tracks marking ground survey locations.

susceptibility values for the two dykes or sills were above in the range $60 \times 10^{-3}$ SI units. The RMS fit for the observed and calculated data for the inversion model was within $0.0005 \%$ as shown on the model. The 3 -Dimensional model of ground magnetic data shows that the spring lies between two east-west trending dykes or inclined sills, approximately $150 \mathrm{~m}$ apart, as seen in the VOXI ${ }^{\circledR}$ model. The magnetic susceptibility values for the dykes or sills were above $100 \times 10^{-3} \mathrm{SI}$ units. The zone with the hot spring and the interpreted fauls had magnetic susceptibility values below $25 \times 10^{-3}$ SI units.

\subsection{Magnetic Susceptibility}

The magnetic susceptibility $\chi$ values at Siloam were $0.23 \pm 0.07 \times 10^{-3}$ SI units 


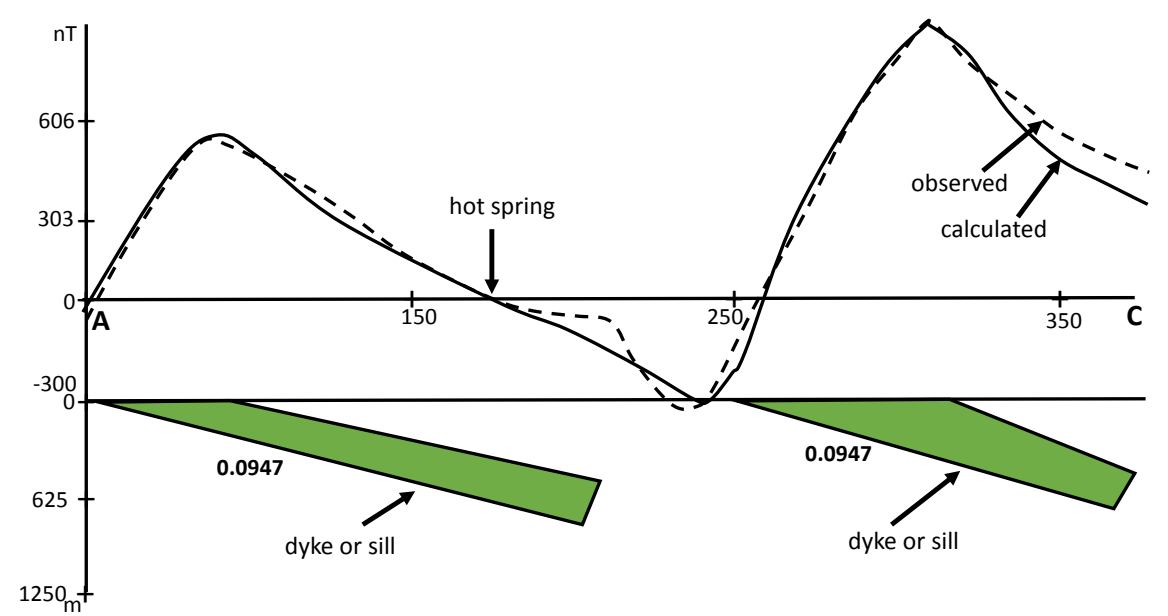

Figure 2. A 2-Dimensional magnetic model for the south to north profile AC located on a section of profile A-B, across the spring, showing dykes dipping to the north. The hot spring is located at $210 \mathrm{~m}$ and the lighter coloured profile is for the observed field data, generated using the Mag2D approach (Nyabeze, Venter, Olivier, \& Motlakeng, 2010).

and $0.05 \pm 0.03 \times 10-3$ SI units for weathered basaltic boulders and metamorphosed rock occurences, respectively (Table 2 ). The basalt and metamorphosed rock samples were located at coordinates $30.19482^{\circ} \mathrm{E}, 22.89387^{\circ} \mathrm{S}$ and $30.19413^{\circ} \mathrm{E}$, $22.89555^{\circ} \mathrm{S}$, respectively. The lower magnetic susceptibility values indicate that the source rock for the metamorphosed samples was subjected to higher source temperatures.

The mean magnetic susceptibility of modelled dykes or sills was $89.9 \pm 10.8 \times$ $10^{-3}$ SI units based on modelling results from using three different software namely Mag2D, VOXI ${ }^{\circledR}$, and ZondMag2D (Table 3).

\subsection{Electromagnetic Surveys}

This section has results for terrain electromagnetic profiling data for the Siloam hot spring recorded in June 2009, May 2011, July 2011, and December 2012. The June 2009 survey involved the recording EC data along accessible areas close to the Siloam hot spring. The other profile surveys in May 2011, July 2011 and December 2012 including one in June 2009, involved the collection of data using ether different dipole separations or coil orientations or a combination of both configurations. The target RMS accuracy for the 2-D conductivity models was $10 \%$ for 10 iterations.

The terrain electromagnetic profiling data for the Siloam hot spring recorded in June 2009 show that the hot spring occurs in a zone with conductivity values above $100 \mathrm{mS} / \mathrm{m}$ with a width of approximately $100 \mathrm{~m}$ to $150 \mathrm{~m}$ (Figure 3). The data were collected in the month of June, during the dry winter season to minimize the effect of meteoric water on terrain electrical conductivity values. Zones with high electrical conductivity values located to the north and south of the hot spring were interpreted to be faults. Zones with low conductivity values were interpreted to be dykes or sills. 
Table 2. Magnetic susceptibility measurements at Siloam hot spring.

\begin{tabular}{ccc}
\hline Item & $\begin{array}{c}\text { Basalt } \\
\chi\left(\times 10^{-3} \mathrm{SI}\right)\end{array}$ & $\begin{array}{c}\text { Metamorphosed } \\
\chi\left(\times 10^{-3} \mathrm{SI}\right)\end{array}$ \\
\hline 1 & 0.23 & 0.05 \\
2 & 0.15 & 0.01 \\
3 & 0.34 & 0.07 \\
4 & 0.19 & 0.03 \\
5 & 0.18 & 0.05 \\
6 & 0.26 & 0.12 \\
7 & 0.35 & 0.07 \\
8 & 0.12 & 0.05 \\
9 & 0.23 & 0.05 \\
10 & 0.23 & 0.02 \\
Mean & 0.23 & 0.05 \\
Std. dev. & 0.07 & 0.03 \\
\hline
\end{tabular}

Table 3. Magnetic magnetic survey site characteristic values.

\begin{tabular}{ccc}
\hline Approach & Softwae & Dyke or Sill $\chi\left(\times 10^{-3}\right.$ SI $)$ \\
\hline 1 & Mag2D & 94.7 \\
2 & VOXI $^{\circledR}$ & 100.0 \\
3 & ZondMag2D $^{\circledR}$ & 75.0 \\
Mean & & 89.9 \\
Std. dev. & & 10.8 \\
\hline
\end{tabular}

The location of profile A-B recorded in June 2009 and B-C and D-E recorded in May 2011, and July 2011, respectively is presented in Figure 3. Profile data for B-C and D-E were used to generate 2-D and 3-D electrical conductivity models. Survey specifications are presented in Table 4.

Electromagnetic conductivity data were collected in June 2009 along a $220 \mathrm{~m}$ long south to north oriented profile B-C, using HD and VD oriented coils with a separation of $20 \mathrm{~m}$ (Figure 4). The 2-D conductivity model indicated that the hot spring and the Siloam Fault were separated by a dyke or sill characterised conductivity values below $35 \mathrm{mS} / \mathrm{m}$. A near surface and sub-horizontal zone with a thickness of approximately $10 \mathrm{~m}$ with EC values above $100 \mathrm{mS} / \mathrm{s}$ was delineated between stations $20 \mathrm{~m}$ and $160 \mathrm{~m}$.

The 2-D modelled results of the terrain electromagnetic profiling data recorded in May 2011 along the $180 \mathrm{~m}$ long profile CB shows that there are near surface zones with high electrical conductivity values above $100 \mathrm{mS} / \mathrm{m}$ (Figure 5). The data was recorded using dipole separations of $20 \mathrm{~m}$ and $40 \mathrm{~m}$ with a horizontal dipole configuration. The conductivity depth model shows a vertical zone near the spring and a well-defined, high conductivity close to the mapped Siloam Fault. 


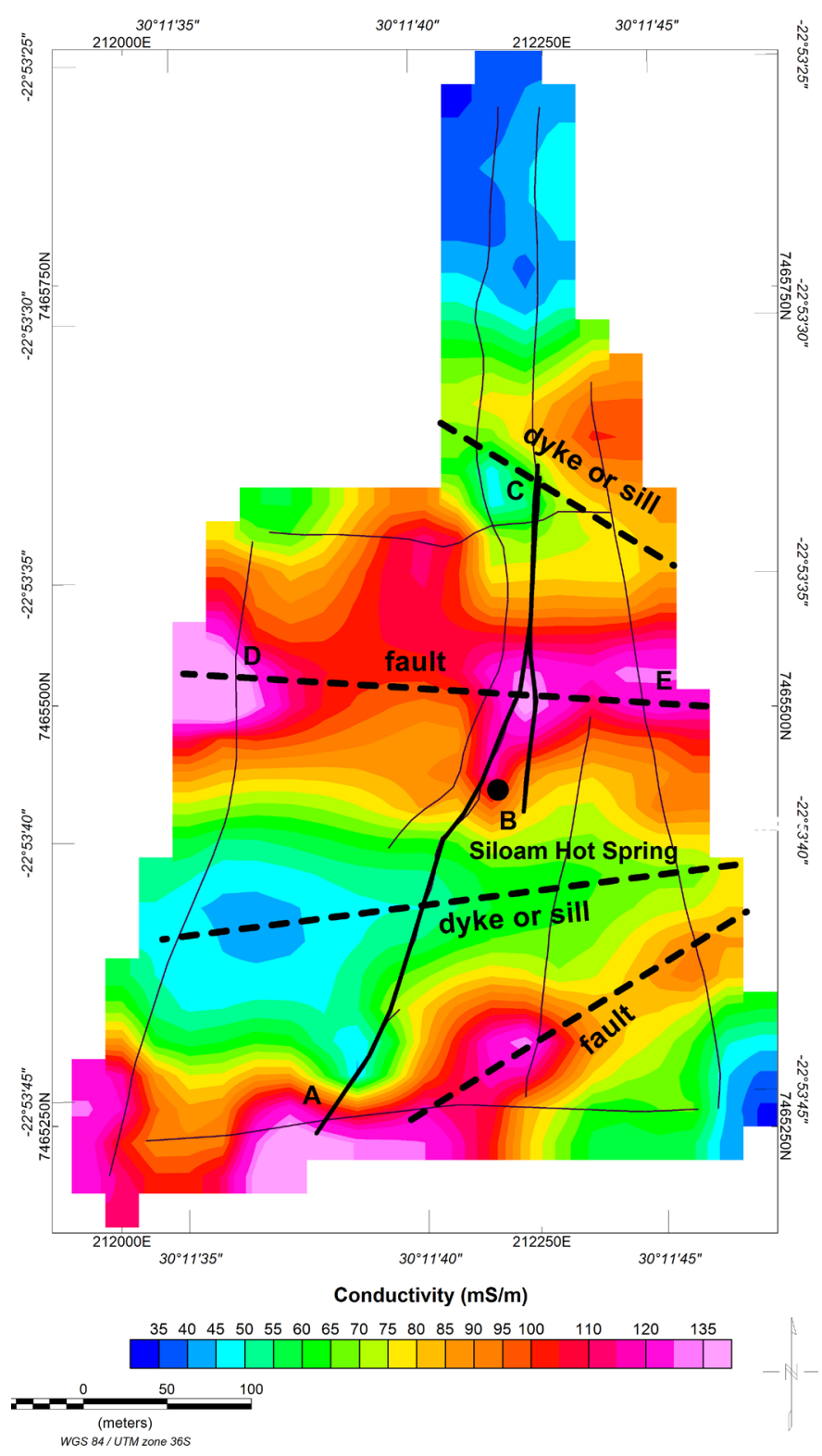

Figure 3. Terrain electrical conductivity profile across the Siloam hot spring surveyed in June 2009 showing EM survey profile, location of the hot spring, as well as interpreted faults, dykes or sills.

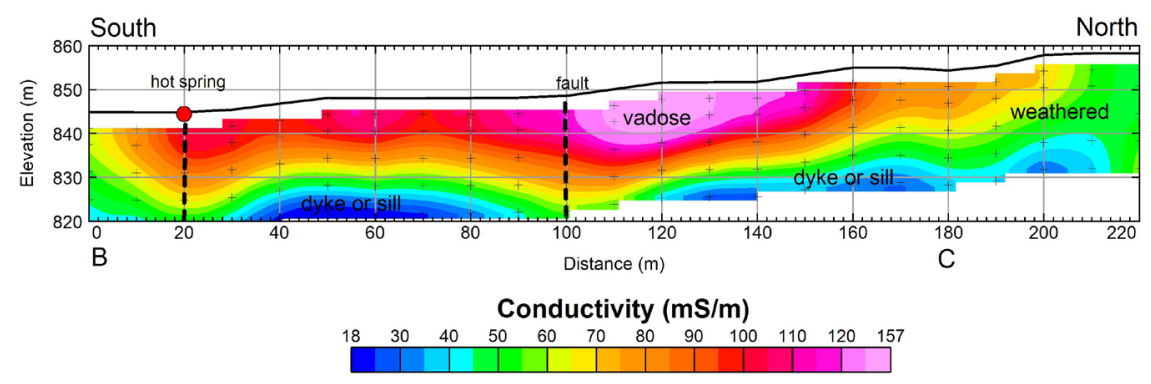

Figure 4. A south-north terrain conductivity profile south to north, B-C across the Siloam hot spring, June 2009, showing high values above $100 \mathrm{mS} / \mathrm{m}$ at the hot spring and Siloam Fault. 
Table 4. EM survey profile details and electrical conductivity data.

\begin{tabular}{cccccccc}
\hline $\begin{array}{c}\text { Profile } \\
\text { Name }\end{array}$ & $\begin{array}{c}\text { Survey } \\
\text { Date }\end{array}$ & $\begin{array}{c}\text { Dipole } \\
(\mathrm{m})\end{array}$ & Coil & Length $(\mathrm{m})$ & Direction & Avg. EC $(\mathrm{mS} / \mathrm{m})$ & $\begin{array}{c}\text { Max. EC } \\
(\mathrm{mS} / \mathrm{m})\end{array}$ \\
\hline B-C & Jun-09 & 20 & HD & 220 & S-N & 85.03 & 135.60 \\
B-C & Jun-09 & 20 & VD & 220 & S-N & 58.28 & 98.40 \\
B-C & May-11 & 20 & HD & 180 & S-N & 102.03 & 152.18 \\
B-C & May-11 & 40 & HD & 180 & S-N & 106.96 & 142.45 \\
D-E & Jul-11 & 20 & HD & 160 & W-E & 131.33 & 191.40 \\
D-E & Jul-11 & 20 & VD & 160 & W-E & 53.01 & 81.40 \\
D-E & Jul-11 & 40 & VD & 160 & W-E & 64.87 & 104.70 \\
A-C & Dec-12 & 10 & HD & 750 & S-N & 42.21 & 98.00 \\
A-C & Dec-12 & 20 & VD & 750 & S-N & 58.59 & 140.00 \\
A-C & Dec-12 & 40 & VD & 750 & S-N & 63.60 & 125.00 \\
\hline
\end{tabular}

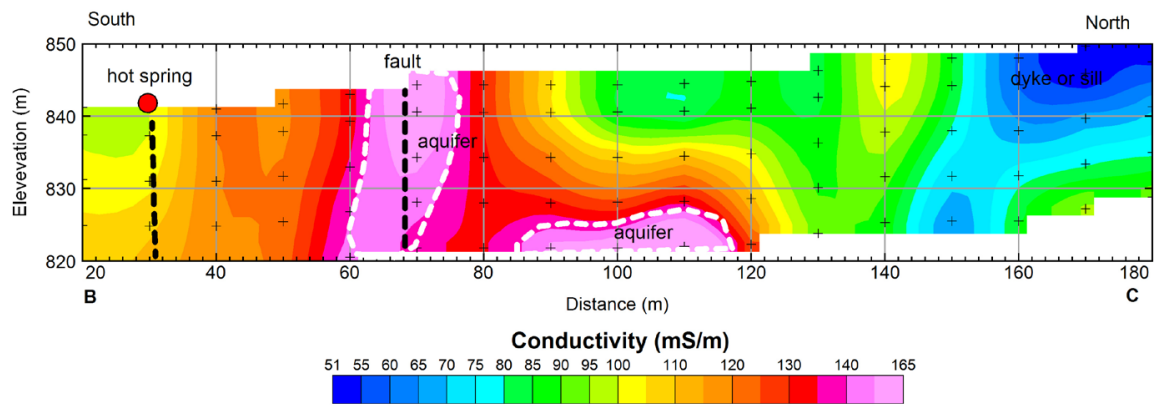

Figure 5. A 2-D conductivity depth model for profile B-C derived from terrain EC data that was recorded in May 2011, showing near vertical high conductivity zones with values $100 \mathrm{mS} / \mathrm{m}$.

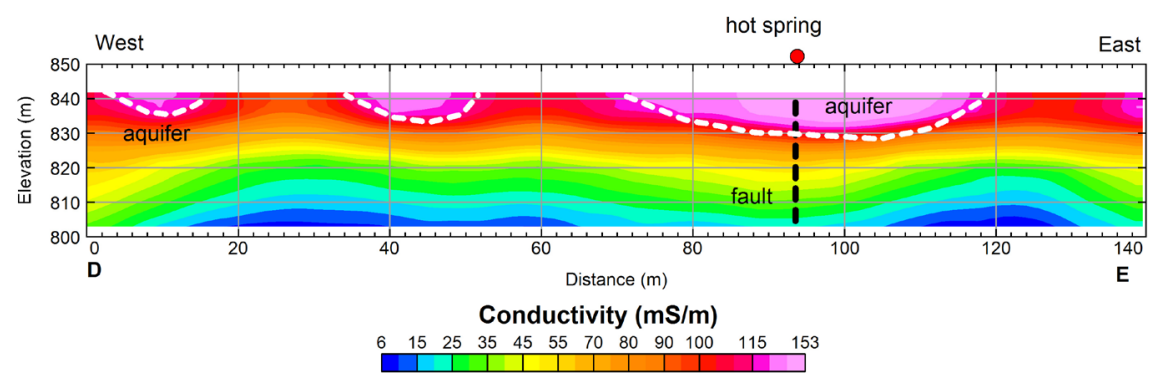

Figure 6. A 2-D conductivity depth model D-E derived from terrain EC data, July 2011, showing near surface conductivity zones with EC values above $100 \mathrm{mS} / \mathrm{m}$.

The terrain electromagnetic conductivity survey along a west to east, $160 \mathrm{~m}$ profile D-E located $50 \mathrm{~m}$ north of the hot spring, as recorded using $20 \mathrm{~m}$ and 40 $\mathrm{m}$ dipole configurations (Figure 6). The $20 \mathrm{~m}$ coil separation survey utilized both VD and HD dipole orientations while a HD set up was used for the $40 \mathrm{~m}$ dipole separation. The near surface high conductivity zones with thickness of approximately $10 \mathrm{~m}$ to $15 \mathrm{~m}$ were delineated as occurring above an elevation of approximately $830 \mathrm{~m}$. 
In December 2012 a survey utilizing 10, 20, and $40 \mathrm{~m}$ coils with $\mathrm{HD}$ configuration was carried out and peak EC values were $98.00 \mathrm{mS} / \mathrm{m}, 140.00 \mathrm{mS} / \mathrm{m}$, and $125.00 \mathrm{mS} / \mathrm{m}$ respectively. The resultant 2 -D model delineated a low conductivity zone that could be associated with a capping sill or dyke; the hot spring at station $175 \mathrm{~m}$ was associated with EC values of approximately $100 \mathrm{mS} / \mathrm{m}$; a zone with EC values above $100 \mathrm{mS} / \mathrm{m}$ was delineated below the inferred location of the Siloam Fault.

\section{Discussion}

The survey area has predominantly east-west trending basaltic and volcanic dykes. The spring occurs between two interpreted north dipping dykes, which are about $150 \mathrm{~m}$ apart with both extending to a vertical depth of approximately $650 \mathrm{~m}$. There is a possibility that the two dykes delineated using the magnetic technique, are faulted segments of a larger dyke, and that the hot water is exploiting fractures in the impermeable dyke material. The delineation of a faulted zone is consistent with results that were obtained for the bedrock variation across the Ikogosi warm spring (Ojo, Olorunfemi, \& Falebita, 2011).

The magnetic susceptibility $\chi$ values for metamophose rock samples at Siloam were $0.23 \pm 0.07 \times 10^{-3}$ SI units and $0.05 \pm 0.03 \times 10^{-3}$ SI units. The modelled dykes or sills at Siloam hot springs had a mean magnetic susceptibility of $89.9 \pm$ $10.8 \times 10^{-3} \mathrm{SI}$ from results of using 3 diffrent software. The existence of traces of ferrimagnetic minerals in water from hot springs was confirmed through an analysis of chemical characteristics of thermal spring occurrences in the research area (Olivier, van Niekerk, \& van der Walt, 2008). The low magnetic susceptibility values in the rage $0.05 \pm 0.03-0.23 \pm 0.07 \times 10^{-3}$ SI units are typical valus for weathered metamorphic rocks. Magnetic susceptibility values in the $89.9 \pm 10.8$ $\times 10^{-3}$ SI range are typical for basalt or dolerite (Clark \& Emerson, 1991). The diffrent values of magntic susceptibility values for volcanic rocks, obtained using three approaches were $94.7 \times 10^{-3}, 94.7 \times 10^{-3}$ and $100 \times 10^{-3}$, respectively indicating the spontaneous nature of levels of magnetisation and different inversion assumptions and approaches. The magnetic susceptibility values for metamorphic and volcanic rock signatures agree with the geology of the Soutpansberg Basin and Limpopo mobile belt (Barker, Brandl, Callaghan, Eriksson, \& van Der Neut, 2006; Ranganai, Moidaki, \& King, 2015).

The results of the electromagnetic survey show that the Siloam hot spring is in an east-west trending conductivity zone with values above $100 \mathrm{mS} / \mathrm{m}$. The east-west zone agreed with results of mapping the Siloam Fault using the electromagnetic method (Brandl, Mitchev, Stettler, Graham, \& Smit, 2001). The width of the conductive zone varies from $100 \mathrm{~m}$ to $150 \mathrm{~m}$. There is a high conductivity zone located in the southern part of the study area with a NE-SW orientation. Near vertical structures with alternating bands of low and high conductivity values were delineated from the conductivity depth sections. High electromagnetic conductivityzones had positive correlations with groundwater bearing structures (Gunnink, Bosch, Siemon, Roth, \& Auken, 2012). The zone 
with high conductivity values could be associated with the water bearing fracture or fault zones whereas the zone with low conductivity could be unfractured rock, dykes or sills. The depth of investigation for the electromagnetic technique that was applied in this study did not exceed $60 \mathrm{~m}$. The limitation in the depth investigation of the frequency domain electromagnetic technique was observed in the results (Spies, 1989).

\section{Conclusion}

The increased resolution of the ground magnetic and electromagnetic survey data methods made it possible to delineate the dykes and faults. Ground magnetic data results indicated that groundwater aquifer was capped by basalt with hot water rising to the surface along possible geological contacts, faults or fractures. The modelling of ground magnetic data showed that the Siloam hot spring occurs between two interpreted north dipping dykes approximately $150 \mathrm{~m}$ apart. The minimum depth of the modelled dykes was approximately $650 \mathrm{~m}$. The lower mean magnetic susceptibility values below $0.23 \pm 0.07 \times 10^{-3}$ SI, for rrock samples indicated that the geological formations at Siloam area were subjected to heat that destroyed ferrimagnetic minerals. The more competent dyke or sill samples had higher mean magnetic susceptibility values of $89.9 \pm 10.8 \times 10^{-3} \mathrm{SI}$ due to ferrimagnetic minerals. High electrical conductivity zones with values above $100 \mathrm{mS} / \mathrm{m}$, close to the Siloam hot spring delineated potentially water bearing zones permeating to depths in the $40 \mathrm{~m}$ to $60 \mathrm{~m}$ range and possibly deeper. The high electrical conductivity zones were due to infiltration of water from the spring and groundwater within the fractured Siloam Fault and weathered bedrock.

\section{Acknowledgements}

This research project was made possible through funding from Water Research Commission (WRC) K5/1959; National Research Foundation (NRF) Grant UID 82443; Mining Qualifications Authority (MQA) and Council for Geoscience. The authors thank Geosoft Inc. is providing software for processing geophysical data.

\section{Conflicts of Interest}

The authors declare no conflicts of interest regarding this article.

\section{References}

Barker, O. B., Brandl, G., Callaghan, C. C., Eriksson, P. G., \& van Der Neut, M. (2006). The Soutpansberg and Waterberg Groups and the Blouberg Formation. In M. R. Johnson, M. R. Anhaeusser, \& C. R. Thomas (Eds.), The Geology of South Africa (pp 301-318). Pretoria: Council for Geoscience; Johannesburg: Geological Society of South Africa.

Brandl, G., Mitchev, S. A., Stettler, E. H., Graham, G., \& Smit, J. P. (2001). Liquefaction-Induced Features along the Siloam Fault, Soutpansberg: Seismic Origin or Ground 
Water Phenomenon? 7th SAGA Biennial Technical Meeting and Exhibition, 2001, 20.

Buschow, K. H. J., \& de Boer, F. R. (2003). Physics of Magnetism and Magnetic Materials (vol. 92, p. 182). New York: Kluwer Academic/Plenum Publishers. https://doi.org/10.1007/b100503

Cano, M. E., Cordova-Fraga, T., Sosa, M., Bernal-Alvarado, J., \& Baffa, O. (2008). Understanding the Magnetic Susceptibility Measurements by Using an Analytical Scale. European Journal of Physics, 29, 345. https://doi.org/10.1088/0143-0807/29/2/015

Clark, D. A., \& Emerson, D. W. (1991). Notes on Rock Magnetization Characteristics in Applied Geophysical Studies. Exploration Geophysics, 22, 547-555. https://doi.org/10.1071/EG991547

Collinson, D. (2013). Methods in Rock Magnetism and Palaeomagnetism: Techniques and Instrumentation (pp. 1-13). Berlin: Springer Science and Business Media.

Dalan, R. A. (2006). Magnetic Susceptibility. In: J. K. Johnson (Ed.), Remote Sensing in Archaeology (pp. 161-203). Tuscaloosa, AL: University of Alabama.

Dearing, J. (1994). Environmental Magnetic Susceptibility. Using the BartingtonMS2 System (p. 207). Kenilworth: Chi Publication.

Ellis, R. G., de Wet, B., \& Macleod, I. N. (2012). Inversion of Magnetic Data for Remanent and Induced Sources. In Australian Society of Exploration Geophysicists (ASEG) EXtended Abstracts 2012 22nd Conference (pp. 1-4). ASEG.

https://doi.org/10.1071/ASEG2012ab117

Exploranium (1995). User's Guide, KT-9 Kappmeter. Exploranium Radiation Detection Systems, 1, 76.

Ferguson, I. J., Young, J. B., Cook, B. J., Krakowka, A. B., \& Tycholiz, C. (2016). Near-Surface Geophysical Surveys at the Duport Gold Deposit, Ontario, Canada: Relating Airborne Responses to Small-Scale Geologic Features. Interpretation, 4, SH39-SH60. https://doi.org/10.1190/INT-2015-0216.1

Geometrics (2007). Geometrics G-856AX Memory magTM Proton Precession Magnetometer Operation Manual (P/N18101-02) (p. 60). San Jose, CA: Geometrics, Inc.

Geometrics (2011). Geometrics G-859AP MINING MAG Cesium Vapor Magnetometer Operation Manual (P/N 25272-OM.) (p. 111). San Jose, CA: Geometrics, Inc.

Geosoft (2013). VOXI Earth Modelling-Running an Inversion (p. 14). Toronto: Geosoft Oasis Montaj.

Geosoft (2014). Oasis Montaj Gridding (p. 21). Toronto: Geosoft Oasis Montaj.

Gunnink, J. L., Bosch, J. H. A., Siemon, B., Roth, B., \& Auken, E. (2012). Combining Ground-Based and Airborne EM through Artificial Neural Networks for Modelling Glacial till under Saline Groundwater Conditions. Hydrology and Earth System Sciences, 16, 3062-3309. https://doi.org/10.5194/hess-16-3061-2012

Kayode, J. S., Adelusi, A. O., \& Nyabeze, P. K. (2011). Horizontal Derivatives of the Ground Magnetic Interpretation in Part of Ilesa Area, Southwestern Nigeria. Scientific Research and Essays, 6, 4163-4171.

Kayode, J. S., Adelusi, A. O., \& Nyabeze, P. K. (2013). Bedrock Depth Estimates from Vertical Derivatives of the Ground Magnetic Studies around Ilesa Area, Southwestern Nigeria. Journal of Emerging Trends in Engineering and Applied Sciences, 4, 594-603.

Lecoanet, H., Lévêque, F., \& Segura, S. (1999). Magnetic Susceptibility in Environmental Applications: Comparison of Field Probes. Physics of the Earth and Planetary Interiors, 115, 191-204. https://doi.org/10.1016/S0031-9201(99)00066-7

Madi, K., Nyabeze, P. K., Gwavava, O., Sekiba, M., \& Zhao, B. (2016). Magnetic and Elec- 
tromagnetic Signatures around PolileTshisa Hot Spring in the Northern Neotectonic Belt in the Eastern Cape Province, South Africa. Acta Geophysica, 64, 943-962. https://doi.org/10.1515/acgeo-2016-0001

McNeill, J. D. (1980). Electromagnetic Terrain Conductivity Measurement at Low Induction Numbers. Technical Note TN-6 (p. 13). Ontario: Geonics.

McNeill, J. D. (1985). EM34-3 Measurements as Two Intercoil Spacings to Reduce Sensitivity to Near-Surface Material: Technical Note TN19 (p. 4). Ontario: Geonics Limited.

McNeill, J. D. (1985b). EM34-3 Survey Interpretation Techniques. Geonics Technical Note $T N-4$ (p. 17). Ontario: Geonics Limited.

Monteiro Santos, F. A. M. (2004). 1-D Laterally Constrained Inversion of EM34 Profiling Data. Journal of Applied Geophysics, 56, 123-134. https://doi.org/10.1016/j.jappgeo.2004.04.005

Monteiro Santos, F. A., Almeida, E. P., Castro, R., Nolasco, R., \& Mendes-Victor, L, (2002). A Hydrogeological Investigation Using EM34 and SP Surveys. Earth Planets Space, 54, 658. https://doi.org/10.1186/BF03353053

Nutter, C. (1981). MAG2D: Interactive 2-1/2-Dimensional Magnetic Modeling Program, User's Guide and Documentation. Salt Lake City, UT: Utah University, Research Institute. https://doi.org/10.2172/5776383

Nyabeze, P. K., Venter, J. S., Olivier, J., \& Motlakeng, T. R. (2010). Characterization of the Thermal Aquifer Associated with the Siloam Hot Spring in Limpopo, South Africa. In O. Totolo (Ed.) (2010), Water Resource Management-2010. Calgary: Acta Press. http://dx.doi.org/10.2316/P.2010.686-059

Ojo, J. S., Olorunfemi, M. O., \& Falebita, D. E. (2011). An Appraisal of the Geologic Structure Beneath the Ikogosi Warm Spring in South-Western Nigeria Using Integrated Surface Geophysical Methods. Earth Sciences Research Journal, 15, 27-34.

Olivier J., van Niekerk H. J., \& van der Walt I. J. (2008). Physical and chemical Characteristics of Thermal Springs in the Waterberg Area in Limpopo Province, South Africa. Water $S A, 34,166-171$.

Peters, L. J. (1949). The Direct Approach to Magnetic Interpretation and Its Practical Application. Geophysics, 14, 290-320. https://doi.org/10.1190/1.1437537

Ranganai, R. T., Moidaki, M., \& King, J. G. (2015). Magnetic Susceptibility of Soils from Eastern Botswana: A Reconnaissance Survey and Potential Applications. Journal of Geography and Geology, 7, 45. https://doi.org/10.5539/jgg.v7n4p45

Spies, B. R. (1989). Depth of Investigation in Electromagnetic Sounding Methods. Geophysics, 54, 872-888. https://doi.org/10.1190/1.1442716

Telford, W. M., Geldart, L. P., \& Sheriff, R. E. (1990). Applied Geophysics (Vol. 1, p. 770). Cambridge, MA: Cambridge University Press. https://doi.org/10.1017/CBO9781139167932

Zond (2010). ZondMag2D User Manual (p. 49). Saint-Petersburg: Zond Geophysical Software. 